\title{
A EDUCAÇÃO AMBIENTAL POR MEIO DA LUDICIDADE: UMA EXPERIÊNCIA EM ESCOLAS DO ENTORNO DO PARQUE ESTADUAL DO UTINGA
}

Maria da Conceição Ferreira BAÍA ${ }^{1}$

IEMCI/UFPA

concibaia@gmail.com

Luiza NAKAYAMA ${ }^{2}$

IEMCI/UFPA

lunaka@ufpa.br

Resumo: Um dos principais problemas da sociedade contemporânea é a degradação do meio ambiente. A humanidade vive diante de um grande desafio: a preservação dos recursos naturais e consequentemente a preservação de sua própria existência. Diante desse quadro, a Educação Ambiental (EA) se apresenta como uma forma mais abrangente e completa de educar. Neste contexto, a Associação Novo Encanto, em parceria com a Secretária Estadual de Meio Ambiente (SEMA), planejaram a execução de ações para os alunos do ensino fundamental de escolas públicas de Ananindeua - PA, localizadas no entorno do PAB, com o objetivo de estudar o uso do lúdico como estratégia para sensibilizar essas crianças para a importância do local, como espaço de lazer, de reserva ambiental de biodiversidade e recursos hídricos.

Palavras-chave: Ludicidade. Educação Ambiental. Ensino Fundamental.

Abstract: One of the main problems of contemporary society is the degradation of the environment. Humanity is facing a big challenge - the preservation of natural resources and consequently the preservation of his own existence. Given this situation, the Environmental Education (EE) is presented as a way to educate more in a

\footnotetext{
${ }^{1}$ Especialista em Educação Ambiental e Uso Sustentável dos Recursos Naturais do Núcleo de Meio Ambiente da Universidade Federal do Pará - NUMA/UFPA, integrante voluntária da ONG Associação Novo Encanto de Desenvolvimento Ecológico, participante do Grupo de Estudo e Pesquisa em Educação Ambiental (GPEEA- Sala Verde Pororoca), IEMCI/UFPA.

${ }^{2}$ Orientadora do programa de pós-graduação em Educação, em Ciências e Matemáticas, coordenadoradoGPEEA-SalaVerde Pororoca-IEMCI/UFPA.E-mail:sverdepororoca@ ufpa.br
} 
comprehensive and complete way. In this context, the "Novo Encanto" Association in partnership with the State Secretary of Environment (SEMA) perform planned actions for elementary school students from public schools in Ananindeua - PA, located around the PAB, with the aim to study the use of the playful as a strategy to sensitize the children of the importance of the place as a space for recreation, environmental reserve, biodiversity and water resources.

Keywords: Playfulness. Environmental Education. Fundamental Education.

\section{Introdução}

O Tratado de Educação Ambiental (EA) para Sociedades Sustentáveis e Responsabilidade Global, aprovado em plenária em 06 de junho de 1992, diz textualmente:

Consideramos que educação ambiental para uma sustentabilidade equitativa é um processo de aprendizagem permanente, baseado no respeito a todas as formas de vida. Tal educação afirma valores e ações que contribuem para a transformação humana e social e para a preservação ecológica. Ela estimula a formação de sociedades socialmente justas e ecologicamente equilibradas, que conservem entre si relação de interdependência e diversidade. Isso requer responsabilidade individual e coletiva a nível local, nacional e planetário (Tratado de Educação Ambiental para Sociedades Sustentáveis e Responsabilidade Global, 1992). ${ }^{3}$

Este conceito deixa claro que por definição a EA é apontada como um processo de aprendizagem permanente com afirmação de valores que contribuem para a transformação humana e social e requer responsabilidade individual e coletiva, portanto, precisa ser implementada na sociedade de forma ampla, buscando sua consolidação. Definida e recomendada mundial e nacionalmente pelos órgãos competentes

${ }^{3}$ Documento elaborado pelo Grupo de Trabalho das Organizações Não-Governamentais, reunido para este fim, no Rio de Janeiro, de 3 a 14 de junho de 1992. 
oficiais e da sociedade civil, a EA tem-se inserido gradualmente em nossa sociedade por meio de programas e projetos desenvolvidos em escolas, empresas, organizações não governamentais (ONGs) e instituições ligadas ao poder público seja na esfera municipal, estadual ou federal.

Um importante passo foi dado com a Constituição de 1988, quando a EA se tornou exigência a ser garantida pelos governos federal, estadual e municipal (artigo 225, \10, VI): "promover a educação ambiental em todos os níveis de ensino e a conscientização pública para a preservação do meio ambiente":

\section{Do Meio Ambiente}

Art. 225 - Todos têm direito ao meio ambiente ecologicamente equilibrado, bem de uso comum do povo e essencial à sadia qualidade de vida, impondo-se ao Poder Público e à coletividade o dever de defendê-lo e preservá-lo para as presentes e futuras gerações.

Outro importante fato para consolidação da EA no Brasil foi a realização da Conferência das Nações Unidas sobre Meio Ambiente e Desenvolvimento, no Rio de Janeiro em 1992 (Eco - 92), conferência internacional que marcaria o futuro das políticas ambientais mundiais e nacionais.

Um dos temas mais falados e discutidos na Eco -92 foi a EA: sua importância, sobre os meios de se chegar a ela, sobre seus princípios e recomendações. Discutiu-se como desenvolver a EA em organizações não-governamentais: na realização de eventos; na sua implementação no ensino formal e não formal.

Talvez a maior importância dessa Conferência para o Brasil tenha sido a atenção dada ao evento pela mídia nacional, o que fez despertar na população o interesse pelas questões ambientais. A partir desse evento a introdução do aspecto ambiental no processo educativo veio ocorrendo gradativamente manifestando-se sob diversas formas, principalmente quando o Governo por meio do Ministério da Educação criou os Parâmetros Curriculares Nacionais com o objetivo de incluir a EA, de maneira transversal, no currículo das séries iniciais, para introduzir um

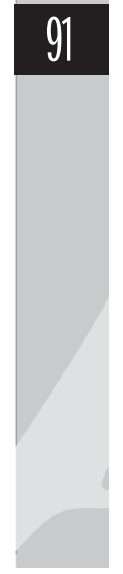


processo de inovação educativa, envolvendo escolas, pais, governos e sociedade de forma a impulsionar uma transformação positiva no sistema educativo brasileiro, com a intenção de ampliar e aprofundar um debate educacional.

Os Parâmetros Curriculares Nacionais - PCNs - foram elaborados procurando, de um lado, respeitar diversidades regionais, culturais e políticas existentes no país e, de outro, considerar a necessidade de construir referências nacionais comuns ao processo educativo em todas as regiões brasileiras. Com isso, pretendeu-se criar condições, nas escolas, que permitissem aos nossos jovens ter acesso ao conjunto de conhecimentos socialmente elaborados e reconhecidos como necessários ao exercício da cidadania.

Nesse contexto, a preocupação em relacionar a educação com a vida do aluno - seu meio, sua comunidade - não é novidade. Ela vem crescendo especialmente desde a década de 1960 no Brasil; exemplo disso são atividades como os "estudos do meio". Porém, a partir da década de 1970, com o crescimento dos movimentos ambientalistas, passou-se a adotar explicitamente a expressão "Educação Ambiental”, para qualificar iniciativas de universidades, escolas, instituições governamentais e nãogovernamentais por meio das quais se busca conscientizar setores da sociedade para as questões ambientais. (PCN, Meio Ambiente, 1995).

Destacamos que a Escola é um importante espaço para implementar a EA, visando a formação de agentes multiplicadores; essa questão tem sido uma preocupação constante daqueles que acreditam na possibilidade de vencer a crise ambiental. O professor é uma peça chave nesse processo, devendo ser encarado como um elemento essencial e fundamental. Sobre essa questão Medina (1994, p. 33) afirma que "o professor é o principal ator das mudanças educativas propostas".

Silva (2005, p. 37), em seu artigo, "Múltiplas falas, saberes e olhares", apresenta alguns princípios considerados fundamentais para o desenvolvimento da EA, entendida como educação para a construção de sociedades sustentáveis, afirmando que ela deve:

[...] permitir a aproximação das práticas culturais realizadas em diversos ambientes. Na medida em que essas práticas estarãodeterminandoofazerpedagógico a ser desenvolvido nas escolas, é aproximação 
entre culturas diferentes que cria possibilidades de ampliação da tolerância às diferenças. De certo modo, é isso que falta às iniciativas de educação ambiental: uma compreensão ampliada dos processos naturais e de sua relação com a manutenção da vida. Algo que supere a mera retórica discursiva e amplie-se para o campo da sensibilidade humana em relação aos fenômenos multidimensionais que compõe a vida.

A EA é uma importante ferramenta para alterar o quadro atual de degradação ambiental, cabe ao profissional de educação a tarefa de tornar o processo de aprendizagem adequado às situações de vida do aluno. Dias (1998, p. 130) corrobora neste aspecto quando afirma que "a aprendizagem será mais significativa se atividade estiver adaptada concretamente às situações da vida real da cidade, ou do meio, do aluno e do professor”.

A EA não deve se limitar a repassar informações ou mostrar apenas o caminho que o professor considera o mais correto. Deve sim, envolver todo o coletivo escolar em um processo de inovação educativa, preparando o aluno para tomar consciência de si mesmo, dos outros, da natureza e da sociedade. Medina deixa claro este aspecto ao afirmar que:

Ao planejar as atividades de Educação Ambiental, o professor deverá considerar a necessidade de construção de conhecimentos significativos e o propósito e a finalidade que o está conduzindo a selecionar para ensinar um conteúdo específico, um conceito e ou uma habilidade concreta, em um determinado nível cognitivo, para um grupo de estudantes num contexto espaço-temporal específico (MEDINA, 2002, p. 62).

Em sua obra, Vivências Integradas com o Meio Ambiente, Telles (2002, p. 41) menciona que "as diretrizes metodológicas existentes em Educação Ambiental são muito diversificadas e estão muitas vezes distantes das reais necessidades das comunidades com as quais se pretende desenvolver um projeto de trabalho."

Uma das metodologias alternativas que consideramos válida para desenvolver atividades em EA com crianças é o uso da ludicidade. Santos (2008, p. 14) relata que os educadores são unânimes em afirmar que a

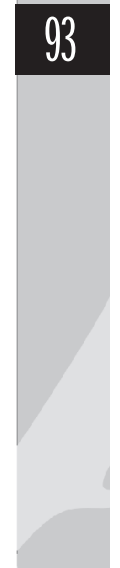


educação é falha, porque rejeitam o ensino pela via do treinamento, da racionalidade excessiva, da repressão e da massificação. Por outro lado, são unânimes também em considerar a ludicidade como uma estratégia viável que se adapta a novas exigências da educação.

Portanto, ao fazer EA o profissional deve procurar utilizar e valorizar as metodologias alternativas que se adaptem a realidade do meio de vida do aluno, de forma a promover o crescimento da consciência ambiental, aumentando a possibilidade das comunidades participarem dos processos decisórios, como forma de fortalecer sua responsabilidade no controle da degradação ambiental. Nesse sentido, cabe destacar, que a EA assume cada vez mais uma função transformadora para a promoção do desenvolvimento sustentável.

\section{O lúdico no processo de ensino-aprendizagem na educação ambiental}

Segundo Ferreira (1975, p. 855), a palavra lúdico refere-se a/ou que tem o caráter de jogos, brinquedos e divertimentos. É relativa também à conduta daquele que joga, que brinca e que se diverte. Por sua vez, diversos teóricos afirmam que a função educativa do jogo oportuniza a aprendizagem do indivíduo, seu saber, seu conhecimento e sua compreensão de mundo. Neste sentido, o lúdico não pode ser visto somente como diversão, o seu desenvolvimento facilita os processos de socialização, comunicação, expressão e construção do conhecimento.

No mundo globalizado, a massificação da televisão, os jogos eletrônicos, os jogos em rede e a internet têm reduzido a importância e o espaço da brincadeira no processo de crescimento e vida da criança. Sobre este aspecto, Santos contribui com a seguinte afirmação:

\footnotetext{
A ludicidade, tão importante para a saúde mental do ser humano, precisa ser mais considerada; o espaço lúdico para a criança está merecendo maior atenção, pois é o espaço para a expressão mais genuína do ser, é o espaço da relação afetiva com o mundo, com as pessoas, com os objetos e com ele mesmo. (SANTOS, 2008, p. 157).
} 
Quando nos reportamos à infância, logo nos lembramos das brincadeiras, jogos, cantigas de roda, brincadeiras de rua, de correr, de pular, de procurar, de pegar - e muitas outras que estão registradas com carinho em nossa memória. Isso nos faz acreditar que um dos maiores prazeres na infância é a brincadeira, já que o brincar é um ato natural, espontâneo e instintivo, toda criança o faz: a brincadeira é um dos fatos que marcam a infância de toda criança.

Para reforçar a importância do lúdico no desenvolvimento da criança, mencionamos a contribuição de Guerra et al. (2007, p. 8), quando cita Buscaglia (1997), comentando o seguinte: "parece paradoxal, que muitos educadores e pais diferenciem ainda o tempo de aprender do tempo de brincar, sem perceber o elo vital que há entre eles".

O direito de brincar é garantido na Declaração Universal dos Direitos da Criança (1959), que em seu princípio VII afirma que: “[...] a criança deve desfrutar plenamente de jogos e brincadeiras os quais deverão estar dirigidos para educação; a sociedade e as autoridades públicas se esforçarão para promover o exercício deste direito".

Pulaski (1980) em sua obra, Compreendendo Piaget, menciona o uso de práticas lúdicas com crianças dizendo que esse processo é válido quando bem aplicado, pois, além do lazer, o lúdico é um método de desenvolvimento intelectual.

Kishimoto (2002, p. 19) nos relata que a infância é, também, a idade do possível. Pode-se projetar sobre ela a esperança de mudança, de transformação social e renovação moral, mostrando-nos o lúdico como um instrumento que permite às crianças a representação de realidades. Afirma ainda que, os brinquedos expressam, preferencialmente, personagens sob forma de bonecos, como manequins articulados ou super-heróis, misto de homens, animais, máquinas e monstros.

A Promulgação da Lei de Diretrizes e Bases da Educação Nacional (LDB/1996) e a divulgação dos Parâmetros Curriculares Nacionais nortearam uma série de reformulações na educação, o que, segundo Santos (2008, p. 14), "permitiu o repensar pedagógico e, neste repensar, ficou muito evidenciado o uso das atividades lúdicas como estratégia para a construção do conhecimento".

A metodologia lúdica vem sendo utilizada não apenas como espetáculo, mas como estratégia educacional. Oliveira (1993) em seu livro,

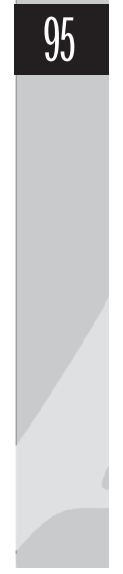


"Vygotsky: aprendizado e desenvolvimento um processo sócio histórico", afirma que a aquisição do conhecimento se dá através das zonas de desenvolvimento: a real e a proximal, sendo a zona de desenvolvimento real a do conhecimento já adquirido - é o que a pessoa traz consigo -, já a proximal, só é atingida, de início, com o auxílio de outras pessoas mais "capazes", que já tenham adquirido esse conhecimento. Esse autor conclui que "O brinquedo cria uma Zona de Desenvolvimento Proximal na criança” (p. 67).

Pulaski (1980), Kishimoto (2002), Santos (2008), entre outros, têm enfatizado a importância do lúdico: apontando-o como um valioso instrumento que permite a inserção da criança no processo de ensinoaprendizagem, fazendo-nos crer que o lúdico como metodologia promotora da capacidade e potencialidade da criança deve ocupar um lugar especial na prática pedagógica, tendo como espaço privilegiado a sala de aula.

Consideramos que a escola, no momento em que ensina e valoriza o ato de brincar, através de atividades prazerosas e divertidas, está estimulando desafios por meio das relações de cooperação, reforçando a preparação dos alunos para a vida, consequentemente contribuindo para a formação de cidadãos responsáveis, cientes dos seus direitos e deveres.

Para completar estas considerações sobre o brincar, o brinquedo e a brincadeira trazemos as ideias de Kishimoto (2002, p. 37), para quem o "brinquedo em sua função educativa ensina qualquer coisa que complete o indivíduo em seu saber, seus conhecimentos e sua apreensão do mundo."

A ludicidade hoje tem sido utilizada com crianças, jovens e adultos em diversas instituições desde a escola, hospitais, empresas, até universidades, demonstrando a seriedade do lúdico. Enfim, embasados nos estudos aqui expostos compreendemos que contemplar a brincadeira como princípio norteador nas atividades de EA possibilita a construção do processo de desenvolvimento no ensino-aprendizagem valorizando a linguagem única e universal que é a brincadeira.

\section{Metodologia}

A ONG Novo Encanto executou, em parceria com a Secretaria Estadual do Meio Ambiente (SEMA-PA), uma ação educativa no PAB, 
envolvendo várias escolas públicas de ensino fundamental do entorno, por ocasião dos festejos do Dia Mundial da Água, no dia 20 de março de 2008.

Nesse dia, as crianças, auxiliadas pelos monitores, realizaram as seguintes atividades: 1) pintaram desenhos ecológicos; 2) construíram um painel utilizando gotas de água de papel, no qual escreveram o que poderiam fazer para preservar a água; 3 ) assistiram a uma peça de teatro de fantoches apresentada pela Companhia de Saneamento do Pará (COSANPA); 4) deram um abraço simbólico nos lagos Bolonha e Água Preta, os mananciais que abastecem Belém.

Em outro momento, enviamos ofício à direção das escolas de Ensino Fundamental João XXIII, Escola Cristo Rei e Escola Municipal Terezinha Souza, solicitando autorização para realizar ações, as quais seriam operacionalizadas no ambiente escolar, durante as aulas.

Efetivamos diagnose nesse primeiro contato, identificando aspectos como infraestrutura, atuação pedagógica e os problemas ambientais vivenciados. A partir dessas informações, planejamos ações para alunos da $1^{\text {a }}$ a $3^{\text {a }}$ séries.

Dando continuidade ao trabalho, elaboramos o planejamento das atividades: agendamento de datas, a forma de realização do trabalho, aspectos infraestruturais e materiais (de consumo e permanente) necessários.

Nesse artigo, por questões didáticas, dividiremos as atividades desenvolvidas nas três escolas em momentos, embora algumas tenham sido efetivadas simultaneamente. Salientamos também que a Roda de Conversa foi realizada, após cada atividade, pois foi o momento de avaliação e reflexão do conteúdo ministrado.

Ressaltamos que cada momento de ação foi descrito considerando-se: a apresentação, a interação, a participação, a reação, enfim, tudo que aconteceu durante o processo. Foi construído um roteiro de observação para servir de guia.

Para coletar informações e impressões dos alunos fizemos perguntas para a turma ao término de cada atividade. Solicitamos também que realizassem desenhos focalizados no tema abordado. Os professores

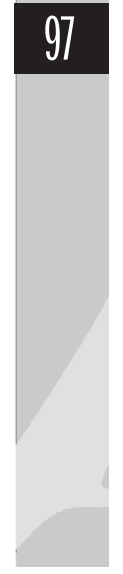


participaram ativamente das atividades, esclarecendo dúvidas dos seus alunos.

Realizamos também pesquisas in loco, conversas informais com professores, alunos, funcionários, membros da direção e coordenação da escola. Todos esses dados foram registrados em um "diário de bordo" e em fotografias.

Para preservar a identidade dos alunos e professores que participaram deste estudo, todos os nomes de pessoas citadas são fictícios, mas os nomes das escolas são reais.

A metodologia utilizada na investigação foi à pesquisa qualitativa do tipo pesquisa ação participativa, analisada de acordo com Brandão (2006), porque esta prevê o envolvimento efetivo dos sujeitos, participantes na dinâmica da pesquisa.

\section{Atividades na escola}

Os recursos pedagógicos utilizados para abordar o tema da preservação do $\mathrm{PAB}$ estão sumarizados na Tabela 1. Nessas atividades participaram os membros da Nova Encanto e professores das turmas envolvidas.

Tabela 1. Atividades de EA desenvolvidas nas escolas do município de Ananindeua - Pará, no ano de 2008.

\begin{tabular}{l|l|c|c|c}
\hline \multicolumn{1}{c|}{ Escolas } & \multicolumn{1}{|c|}{ Atividade Desenvolvida } & Série & $\mathrm{N}$ & $\mathrm{CH}$ \\
\hline \multirow{3}{*}{ Escola João XXIII } & Exibição de vídeo, gincana, & $1^{\mathrm{a}}$ & 27 & $30 \mathrm{~min}$ \\
& mímica e roda de conversa. & $2^{\mathrm{a}}$ & 26 & $50 \mathrm{~min}$ \\
& $3^{\mathrm{a}}$ & 35 & $60 \mathrm{~min}$ \\
\hline \multirow{2}{*}{ Escola Cristo Rei } & Jogo do passa bola, contação & EI & 23 & $30 \mathrm{~min}$ \\
& de histórias, roda de conversa. & $2^{\mathrm{a}}$ & 30 & $50 \mathrm{~min}$ \\
& Exibição de vídeo, gincana, & $3^{\mathrm{a}}$ & 36 & $40 \mathrm{~min}$ \\
& mímica e roda de conversa. & & & \\
\hline \multirow{2}{*}{ Escola Terezinha } & Teatro de fantoches & $1^{\mathrm{a}}$ & 27 & $60 \mathrm{~min}$ \\
de Souza & & $3^{\mathrm{a}}$ & 26 & $60 \mathrm{~min}$ \\
\hline \multicolumn{2}{l|}{ Total } & & 265 & $440 \mathrm{~min}$ \\
\hline
\end{tabular}

$\mathrm{N}=$ número de participantes; $\mathrm{CH}=$ Carga Horária; EI= Educação Infantil. 


\subsection{Vídeos}

O som e a imagem estão presentes diariamente na vida de todos nós, seja pela televisão, rádio, cinema e ultimamente pela internet. Este fato nos motivou a escolher o vídeo como ferramenta para nortear o trabalho nas escolas.

Utilizamos este recurso audiovisual com as turmas de $1^{\mathrm{a}}$ a $3^{\mathrm{a}}$ série, como elemento introdutório em sala de aula, para transmitir a mensagem da conservação do PAB e dos mananciais, funcionando como um instrumento de apoio em todas as atividades.

O vídeo como ferramenta no processo de ensino aprendizagem vem sendo muito utilizado. Parra et al (1985, p. 38) acredita que: "se bem produzidos e utilizados, os auxiliares audiovisuais podem criar uma atmosfera que envolve emocionalmente o aluno, quase um pré-requisito para conseguir levá-lo a um trabalho ativo e autoiniciado.

Vale ressaltar a importância dos sentidos na comunicação para o processo de ensino-aprendizagem. Neste contexto, Parra et al (1985, p. 42) comenta que "a audição e a visão são responsáveis por $70 \%$ da nossa comunicação diária e nesse sentido poderia ser usado o vídeo ou filme educativo, de modo que favoreça uma contribuição efetiva à aula".

As luzes apagadas e o clima de cinema dentro da sala de aula, colaboraram para gerar uma grande expectativa de tal modo que a turma permaneceu concentrada. Além disso, os atrativos das imagens e do som da natureza do PAB, sem dúvida, fascinaram os alunos que, com o olhar atento, assistiram a exibição do vídeo. Percebemos que os alunos receberam bem a transmissão da mensagem. Ao final foi possível ouvir nas vozes dos alunos expressões como: "Eu gosto muito de filmes, no filme nós vimos o Parque, a gente pode passear lá, mas não pode jogar lixo lá nem nos lagos e nem na escola" (Virginia, 08 anos, $2^{\mathrm{a}}$ série).

\subsection{Mímica ou linguagem gestual}

A mímica ou linguagem gestual foi também um dos recursos que utilizamos com os alunos de $1^{\mathrm{a}}$ a $3^{\mathrm{a}}$ série, visando chamar atenção para 
a importância da água nas atividades de EA. Prado (2009, p. 2) em seu artigo: "A utilização da mímica como recurso psicopedagógico" relata que: "a linguagem gestual nasceu com o homem primitivo e renasce todos os dias como parte da necessidade do mesmo se expressar, comunicar e ajudar no desenvolvimento geral da comunidade".

Para esta atividade pedimos a manifestação espontânea e quatro alunos se prontificaram a dramatizar as seguintes frases para turma adivinhar:

"Água mole em pedra dura, tanto bate até que fura."

“Águas passadas não movem moinho.”

"Uma mão lava a outra e as duas lavam a cara."

"Quem vai pra chuva é pra se molhar.

Consideramos que esta ferramenta abre um importante canal de comunicação entre o grupo, além de se apresentar como uma brincadeira que encanta as crianças.

Inicialmente os alunos estavam meio tímidos e se recusavam a participar da atividade. Porém, gradativamente, eles entraram em um clima de entusiasmo expressando-se através dos gestos e estabelecendo, dessa forma, um canal de comunicação com os colegas da turma, que reagiam com o mesmo entusiasmo, tentando adivinhar o que a mímica queria expressar, construindo um ambiente de amizade e alegria. Neste sentido, Prado (2009, p. 3) corrobora afirmando que: "O gesto aliado ao que se quer dizer é meio pelo qual se propaga a afetividade e em si abre canais de comunicação entre o ambiente e o sujeito que uma vez 'entusiasmado' torna-se mais receptivo às novas informações ou ao confrontamento de opiniões".

Os alunos acertaram a maior parte das mímicas e lembravam-se da importância da preservação da água com expressões do tipo “... não podemos deixar poluir as águas, temos que jogar limpo com o meio ambiente” (Tereza, 08 anos, $2^{\mathrm{a}}$ série). 


\subsection{Gincana}

Segundo a enciclopédia livre Wikipédia "uma gincana é um tipo de competição recreativa que tem o objetivo de pôr à prova as habilidades físicas ou mentais dos membros de duas ou mais equipes". Escolhemos esta modalidade de brincadeira para realizar atividades de EA com alunos da $3^{\mathrm{a}}$ série. A brincadeira da gincana consistia em responder adivinhações sobre a água, com premiação de brindes, para os acertos. Para esta brincadeira dividimos a turma aleatoriamente em dois grupos.

Felicio et al. (2008), em seu artigo "Gincana lúdica ambiental interdisciplinar: analisando interações e movimentos", reportam-se a gincana afirmando que ela pode ser considerada uma atividade lúdica com características intrínsecas ao jogo. No mesmo trabalho, os autores citam Huizinga (2007), o qual menciona que "a gincana [...] é uma atividade livre, conscientemente tomada 'não séria' e exterior à vista habitual, mas ao mesmo tempo capaz de absorver o jogador de maneira intensa e total".

Os alunos participaram da gincana de modo intenso e com entusiasmo se esforçando para acertar as perguntas: todos queriam falar ao mesmo tempo ansiosos para ganhar os brindes. As perguntas que nortearam a gincana estão listadas na Tabela 2 .

Tabela 2. Conteúdo da brincadeira da gincana desenvolvida em escolas públicas de Ananindeua - PA, em 2008.

\begin{tabular}{|c|c|}
\hline PERGUNTAS & RESPOSTAS \\
\hline 1. Por que os oceanos não merecem confiança? & $\begin{array}{l}\text { Porque eles gostam de fazer } \\
\text { onda. }\end{array}$ \\
\hline 2. Quem é que com o calor fica aguado? & O gelo. \\
\hline 3. O que é que entra na água sem se molhar? & A sombra do sol. \\
\hline 4. Diga uma queda sem consequência? & A queda d' água. \\
\hline $\begin{array}{l}\text { 5. Fale três dicas preciosas para economizar água. } \\
\text { 6. Como podemos preservar a água? }\end{array}$ & $\begin{array}{l}\text { Diversas respostas a respeito da } \\
\text { economia de água. }\end{array}$ \\
\hline 7. Quais os Lagos que abastecem a cidade de Belém? & Bolonha e Água Preta \\
\hline $\begin{array}{l}\text { 8. Por que os lagos Bolonha e Água Preta são } \\
\text { importantes para a nossa vida? }\end{array}$ & $\begin{array}{l}\text { Porque fornecem água para a } \\
\text { população. }\end{array}$ \\
\hline
\end{tabular}

4 Disponível em http://pt.wikipedia.org/wiki/Gincana 
Entre as perguntas feitas a que houve maior número de acertos foi: Fale três dicas preciosas para economizar água. Entre as diferentes respostas, os participantes citaram: fechar as torneiras quando escovam os dentes, tomar banhos curtos, fechar o chuveiro quando está se ensaboando, cuidar dos vazamentos.

Ao procurar falar dos problemas ambientais, alguns alunos apontaram aspectos clássicos da poluição em geral, principalmente os relacionados ao ambiente em que vivem como tratamento inadequado do lixo e da água.

\subsection{Contação de histórias}

Para algumas atividades foram realizadas pequenas modificações de acordo com o público-alvo, por exemplo: na Escola João XXIII, para atender a turma de crianças especiais, foi utilizado a contação de história da Gotinha Pim-plim, de autoria de Gerusa Rodrigues Pinto (2004).

A contação de história estimula a imaginação e desperta o interesse para a leitura, segundo Nakayama et al. (2007, p. 5): "ao contar histórias estamos estimulando a criança à leitura como algo indispensável e natural em sua vida". Ao nosso redor, percebemos que os alunos permaneceram em silêncio ouvindo o desenrolar da história e prestando atenção às figuras do livro. Ao final dela os alunos se emocionaram com a gotinha e declaravam, "ah eu gosto tanto da gotinha Plimplim, ela é importante para mim".

Perguntamos quem tinha dúvidas sobre o que ouviu e avisamos que seria melhor que se manifestassem um de cada vez, mas, ansiosos, falavam todos ao mesmo tempo. As perguntas formuladas pelos alunos eram do tipo: Por que a gotinha Plim-plim desceu da nuvem? A gotinha Plim-plim é a água que bebemos?

Neste aspecto, Nakayama et al. (2007) acreditam que: "A história infantil alimenta a imaginação, aprimora o pensamento e amplia na criança sua compreensão de mundo, auxiliando-a na resolução de conflitos internos, já que ela incorpora o texto literário como parte da própria vida".

\subsection{Jogo do passa a bola}

Em vista de Kishimoto afirmar que: "A utilização do jogo potencializa a exploração e a construção do conhecimento, por contar 
com a motivação interna, típica do lúdico" (2002, p. 37), escolhemos o "Jogo do passa bola" com as turmas de alunos de Educação Infantil.

Nesse jogo, a bola era passada de mão em mão ao som da música. Quando esta era repentinamente interrompida, a criança que estivesse com a bola na mão, teria que pagar a seguinte prenda, responder uma pergunta sobre a preservação do $\mathrm{PAB}$ e seus mananciais, conforme roteiro a seguir:

1. Quais os lagos que abastecem a cidade de Belém?

2. Como podemos preservar a água?

\section{Como devemos economizar água?}

4. Por que os lagos Bolonha e Água Preta são importantes para a nossa vida?

No início dessa atividade, as crianças se mostraram tímidas, mas após alguns momentos tiveram boa interação e esfuziantes passavam a bola com pressa para não receber o "castigo" de responder as perguntas, deixando muitas vezes a bola cair. O clima foi de gargalhadas e ouvíamos com frequência a expressão: "passa a bola, passa a bola!" ou "ah! agora vai ter que responder a pergunta", e assim o jogo seguia com alguns alunos acertando e outros errando as resposta, tudo em um clima descontraído de aprendizagem.

Verificamos que as atividades desenvolvidas foram bem aceitas para as crianças da faixa etária de 08 a 12 anos, entretanto, as crianças com idade inferior a 07 anos tiveram dificuldades de compreender o conteúdo, pois na hora de responder às perguntas da brincadeira do passa bola, relativas à mensagem exibida no vídeo, poucos acertaram.

A partir desta constatação, as instituições responsáveis pela ação decidiram utilizar uma abordagem por meio da arte lúdica, com a apresentação de conteúdos em forma de arte teatral, a qual possibilita a assimilação do entendimento da mensagem sobre a preservação do Parque para crianças de todas as faixas etárias.

Para isso foi planejada e estruturada a abordagem com a utilização do Teatro de Fantoches, não apenas como espetáculo, mas como uma estratégia educacional lúdica. O segundo passo foi a construção do texto, o tema da peça, como seria desenvolvida, a data em que seria apresentada e a forma como o tema seria trabalhado em sala de aula. 


\subsection{O Teatro de Fantoches}

O teatro de fantoches foi encenado apenas na Escola Municipal de Ensino Fundamental Terezinha de Souza como uma estratégia educacional lúdica, pois essa técnica estimula a concentração dos alunos. Sobre essa atividade, Baia et al. (2008), em seu artigo "Discorrendo sobre o lúdico e o Teatro de Fantoches na EA", concluíram que: as crianças se sentiram estimuladas e atraídas pela técnica, concentrando a atenção para o Teatro de Fantoches, inclusive, interagindo com os bonecos numa linguagem simples e humorística.

Elaboramos o conteúdo do texto da peça intitulada: "Naturinha, Quika e João Divino fazem um passeio no Parque Ambiental de Belém”, assim como, a data em que seria apresentada e a forma como o tema seria trabalhado em sala de aula.

No primeiro ato, apresentamos uma situação do cotidiano: Naturinha e Quika, crianças moradoras do bairrovizinho ao PAB, dialogam sobre consumismo e os seus efeitos no meio ambiente. No segundo, o passeio pelo PAB: o personagem João Divino se integra ao grupo. Os personagens, durante o passeio, dialogam mostrando os recursos naturais que existem no local e a importância de sua preservação, enfatizando a questão dos lagos e da água que abastece a cidade de Belém. No terceiro, os personagens dialogam com os alunos por meio de perguntas, aprovando ou corrigindo as respostas dadas pela turma.

Apresentamos o Teatro de Fantoches em duas ocasiões. A primeira rodada foi realizada no dia 16 de maio de 2008, com duas apresentações, sendo a primeira com as turmas da $2^{\mathrm{a}}$ e $3^{\mathrm{a}}$ série e a segunda com duas turmas de alunos da $1^{\text {a }}$ série. A segunda rodada de apresentações foi realizada no dia 16 de outubro do mesmo ano, com três turmas, sendo a apresentação feita em cada turma do ensino fundamental de primeira a terceira série envolvendo ao todo, oitenta e oito alunos.

Em todas as apresentações, a participação das crianças foi muito animada e espontânea, com total interação com os bonecos. Os alunos expressavam suas emoções; nesse aspecto, Ladeira e Caldas (1989, p. 16) relatam que: "Através do boneco, elas expressam as suas próprias emoções, aliviam suas tensões, agem espontaneamente, pondo à mostra sua verdadeira personalidade ao fazer o boneco falar, cantar ou brincar". 
Percebemos que as crianças se sentiram estimuladas e atraídas pela técnica, concentrando a atenção para o Teatro de Fantoches (Figura 10), inclusive, interagindo com os bonecos, influenciando no desenvolvimento do enredo da peça em uma linguagem simples e humorística. Neste aspecto, citamos as contribuições de Guerra et al. (2007, p. 7): "Apesar de haver um roteiro básico como guia a ser seguido, as falas e o comportamento de cada personagem podiam ser diferentes de acordo com a reação dos espectadores".

Ao final das apresentações, além das nossas observações e avaliações, perguntamos para a turma: Qual a mensagem que o teatro de fantoches transmitiu para vocês? E solicitamos que a resposta fosse por meio de um desenho. Além dos desenhos, perguntamos para alguns alunos individualmente: $\mathrm{O}$ que você aprendeu na aula de hoje com o Teatro de Fantoches?

Procuramos dar destaque às imagens dos alunos que além dos desenhos também expressaram depoimentos a respeito da encenação do teatro de fantoches.

Observamos que em todas as representações gráficas continham elementos da natureza e do PAB, com ênfase para os lagos e elementos do meio ambiente. Também ficou evidente que em alguns desenhos retratou-se figuras integrantes do ambiente onde vivem - além dos elementos naturais os alunos consideraram os elementos construídos e o homem.

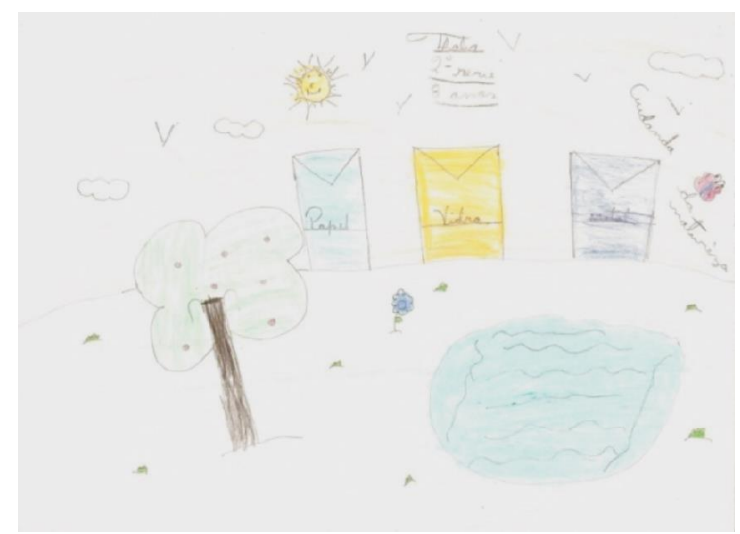

Figura 1. Desenho da aluna Cristina (08 anos) $2^{a}$ série do Ensino Fundamental do turno manhã da Escola Municipal Terezinha de Souza. 
Salientamos na Figura 1, a representação do Parque. No entanto, embora não haja no local recipientes de coleta seletiva de lixo, como foi muito comentado, em vários momentos, a importância do tratamento do lixo, a aluna manifestou em seu desenho esse aspecto. Em seu depoimento, Cristina expressa a mensagem da preservação da natureza e da poluição da água.

- Na aula do teatro de fantoches, eu aprendi que não devemos maltratar a natureza e devemos cuidar bem da água para não poluir, porque depois nós vamos beber essa água.

Os desenhos também nos levam a supor que o teatro de fantoches atingiu o seu objetivo, no sentido de sensibilizar as crianças para a necessidade da convivência em harmonia do homem com o ambiente e de conservar a natureza e o PAB. Este fato é relatado por Guerra et al. (2007, p. 4) citando Galvão (1996): "As crianças parecem receber bem melhor e armazenar com mais facilidade as imagens, quando são apresentadas através de algo que as encante emocionalmente como é o caso do Teatro de Bonecos".

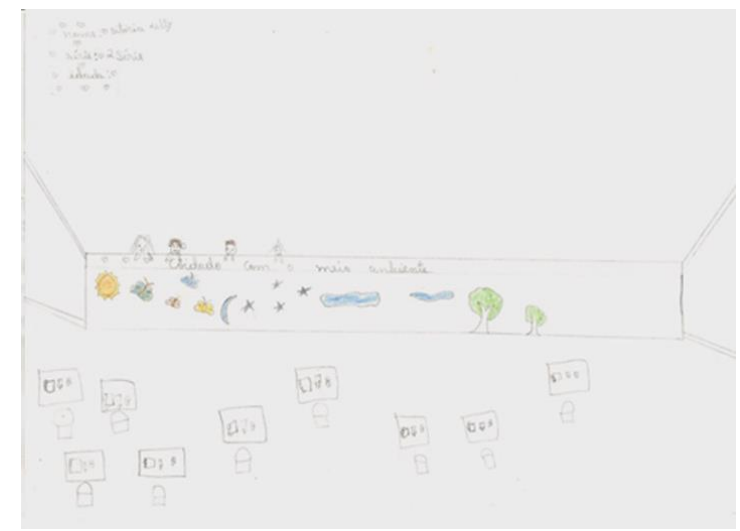

Figura 2. Desenho da aluna Joana (08 anos) da $2^{\mathrm{a}}$ série do Ensino Fundamental, turno manhã da Escola Municipal Terezinha de Souza

Na Figura 2, a aluna Joana reproduz os bonecos e o cenário do teatro de fantoches e acrescenta a frase: "Cuidado com o meio ambiente" demonstrando claramente o seu entendimento da mensagem 
da preservação da natureza. No depoimento a seguir, ela expressa a preocupação com a água e o lixo:

- Eu aprendi que não pode tomar banho no lago, que não pode jogar lixo no Parque e nem nos lagos, pode ir ao Parque pra passear e também não pode fazer muito barulho lá (Joana, 08 anos , $2^{\text {a }}$ Série).

Para complementar, citamos ainda mais dois depoimentos de alunos; podemos observar que eles expressam bem o entendimento da mensagem:

- Eu gostei muito do teatro. Aprendi que a gente não pode comprar muitas coisas, só o necessário, porque causa muito prejuízo no meio ambiente e também muito lixo. (Marina, 09 anos $2^{\mathrm{a}}$ série).

- Aprendi que no Parque a gente pode passear e que não pode jogar lixo na escola, no parque e nos lagos (Maria Eduarda, 08 anos, $2^{\mathrm{a}}$ série).

Neste aspecto, Ladeira e Caldas (1989, p. 16) afirmam que "o teatro de bonecos na escola pode proporcionar ao aluno uma rica e significativa experiência, podendo abrir caminhos para as descobertas e a exploração do mundo que o rodeia."

Os relatos dos professores, da mesma forma, retratam a relevância do teatro de fantoches como uma metodologia que possibilita a abordagem ambiental de maneira lúdica em sala de aula, levando o aluno a relacionar a historinha com os problemas vividos no cotidiano. Assim a EA se apresenta de forma prazerosa e sua assimilação é facilitada por meio da brincadeira. Aliado a este fato, o teatro de fantoches cria a possibilidade de colocar os alunos num mundo imaginário, mas real conforme nos relatam Guerra et al. (2007, p. 7): "Não era raro ouvirmos, entre os alunos dessas escolas, frases como "Não jogue esse papel no chão, você não ouviu o que o Ronaldinho disse?"

A seguir, citamos manifestações de professores à pergunta: Você acha que o Teatro de Fantoches é uma metodologia válida para ser utilizada em EA? 
- Eu acho muito importante trazer o lúdico para dentro da sala de aula transmitindo o aprendizado para os alunos, porque é uma forma de penetrar no mundo da brincadeira e despertar a atenção e o interesse do aluno para a questão do meio ambiente que está aqui na nossa frente (Lúcia, professora da $3^{\mathrm{a}}$ série).

- Eu gostei muito, prendeu o interesse e despertou a atenção. Eles ficaram atentos (as crianças) e se encaixou bem com o conteúdo de Geografia que estou ministrando sobre o meio ambiente (Socorro, professora da $2^{\mathrm{a}}$ série).

- Foi ótima esta atividade! Esse recurso do teatro de fantoches é muito bom; a criança aprende brincando, e qualquer atividade se torna prazerosa (Rosilete, orientadora Pedagógica da Escola Terezinha de Souza).

Portanto, consideramos pertinente os professores se prepararem desde a graduação para ministrar atividades lúdicas como instrumento de ensino-aprendizagem. Por exemplo: Franzoni e Villani (2001), na disciplina Prática de Ensino em Biologia, para alunos do curso de Ciências Biológicas da Universidade Federal de São Carlos, verificaram que inicialmente as licenciandas se mostraram resistentes e pouco interessadas em relação ao estágio que deveria ser desenvolvido. No entanto, no decorrer da disciplina, as alunas estagiárias foram propondo várias atividades lúdicas para os alunos de uma escola pública estadual, na faixa etária de 16 a 18 anos. Assim, concluíram o estágio, expressando seu entusiasmo, por exemplo, no comentário de uma licenciada (p. 16): Conseguimos, por meio do teatro, sensibilizar os nossos alunos. Dessa vez sim, eles ficaram extremamente sensibilizados e até estão pensando no que poderá ser possível fazer para sensibilizar os seus amigos.

\subsection{Roda de Conversa}

No intuito de ouvir a livre expressão dos alunos, realizamos uma roda de conversa sobre a importância do $\mathrm{PAB}$ e sobre o que os estudantes observaram e gostaram, após qualquer atividade de EA (Figura 3). 


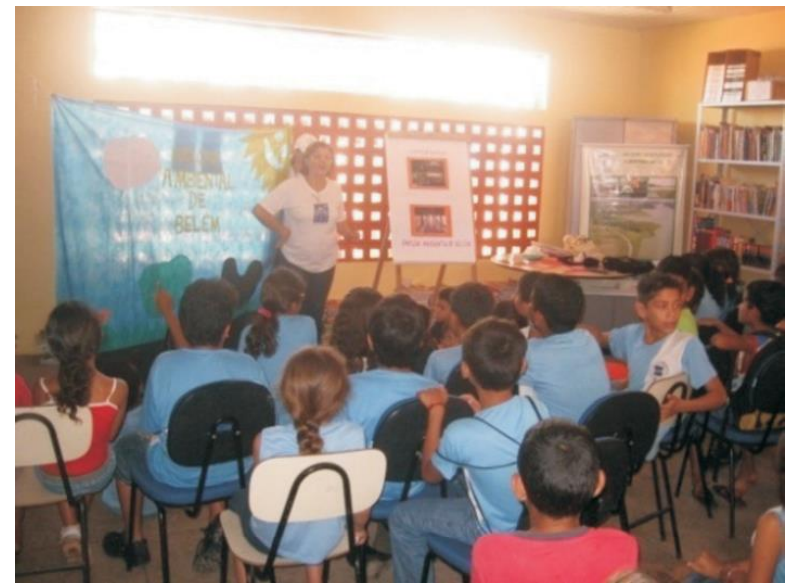

Figura 3 Alunos da $3^{\text {a }}$ série do Ensino Fundamental do turno manhã da Escola Municipal Terezinha de Souza, participando de uma roda de conversa, no dia 16 de maio de 2008.

Perguntamos na roda de conversa, sobre aspectos referentes ao PAB. Os alunos se manifestaram demonstrando reconhecerem os principais problemas, principalmente com relação ao descarte do lixo nas imediações. Vale ressaltarmos a importância da Roda da Conversa neste processo "que tem, entre outras, a função de expressão livre, organização das falas de cada um, interação e autonomia no processo de diálogo "(RECHINELI et al., 2008, p. 3). Além disso, consideramos que a roda de conversa proporcionou um momento de liberdade para a criança se expressar, de contar novidades e curiosidades.

\section{Conclusão}

Partindo do princípio que a predisposição para brincar é parte essencial da natureza infantil, concluímos que a abordagem utilizando metodologias lúdicas possibilita transformar as aulas tradicionais em momentos de alegria e prazer.

O Teatro de Fantoche como instrumento de ensino e aprendizagem em EA foi o mais eficiente em vista de ter despertado o interesse e a participação de todos, resultando em um bom nível de compreensão dos 
alunos de diferentes séries, portanto, concluímos que essa ferramenta pode ser introduzida nas práticas pedagógicas das escolas.

Assim, a ONG Novo Encanto em parceria com a SEMAPA norteará seus futuros trabalhos lúdicos de sensibilização sobre a importância do $\mathrm{PAB}$ em outras escolas do entorno, enfatizando o Teatro de Fantoches, possibilitando criar condições para que a comunidade do entorno compreenda o seu papel como cidadãos e possam colaborar para o uso racional dessa Unidade de Conservação.

Salientamos, porém, que nas intervenções lúdicas é fundamental o papel do educador que precisa estar em sintonia com os alunos e disposto não só a ensinar, mas estar aberto a aprender também. Assim, acreditamos que a formação de professores deve contemplar, desde a sua graduação, atividades de ensino aprendizagem com conteúdos lúdicos.

\section{REFERÊNCIAS}

BRANDÃO, C. R. Pesquisa participante. São Paulo: Brasiliense, 2006.

BRASIL. Ministério da Educação e Cultura. Parâmetros Curriculares Nacionais: Meio Ambiente, 1995.

BRASIL. Lei de Diretrizes e Bases da Educação Nacional, n. 9394/96. São Paulo: Atlas, 1996.

\section{BRASIL. Constituição da República Federativa do Brasil.}

São Paulo: Atlas, 2004.

BUSCAGLIA, L. O paraíso fica perto. In: Teatro de fantoches: uma estratégia em Educação Ambiental, Rio de Janeiro: Nova Era, 1997. Disponível em: http://www.dse.ufpb.br/ea/Masters/Artigo_4.pdf. Acesso em: 29/10/2008.

DIAS, G. F. Educação Ambiental: Princípios e práticas. São Paulo: Gaia, 1993.

FELÍCIO, C. M.; ELIAS, A.A. A. K.; NASCIMENTO, G. B.; QUEIROZ, C. R. A. A.; PEIXOTO, A. J.; SOARES, M. H. F. B. Gincana lúdica 
ambiental interdisciplinar: analisando interações e movimentos. Disponível em: http://www.iesa.ufg.br/congea/cong/nupeat_TRAB/ id000000000000148r0.pdf. Acesso em: 11/04/2009.

FERREIRA, A. B. H. Novo dicionário Aurélio. Rio de Janeiro: Nova Fronteira, 1975.

FRANZONI, M.; VILLANI, A. Uma experiência de grupo na formação inicial de professores. In: Educação em Ciências: da pesquisa à prática docente. NARDI, R. (Org.). São Paulo: Escrituras, 2001.

GUERRA, R. A. T.; GUSMÃO, C. R. C.; SIBRÃO, E. R. Teatro de fantoches: uma estratégia em Educação Ambiental. Disponível em: http://www.dse.ufpb.br/ea/Masters/Artigo_4.pdf. Acesso em: 29/10/2008.

GALVÃO, M. N. C. Possibilidades Educativas do Teatro de Bonecos nas escolas públicas de João Pessoa. In: Teatro de fantoches: uma estratégia em Educação Ambiental, 1996. Disponível em: http://www.dse.ufpb.br/ ea/Masters/Artigo 4.pdf. Acesso em: 29/10/2008.

HUIZINGA,J.Homoludens: ojogo como elemento da cultura. São Paulo: Perspectiva, 2007. In: Gincana lúdica ambiental interdisciplinar: analisando interações e movimentos. Disponível em: http://www.iesa. ufg.br/congea/cong/nupeat TRAB/id000000000000148r0.pdf. Acesso em: 11/04/2009.

KISHIMOTO, T. M. Jogo, brinquedo, brincadeira e a educação. São Paulo: Cortez, 2002.

LADEIRA, Idalina; CALDAS, Sarah Souza P. Fantoche \& Cia. São Paulo: Scipione, 1989.

MEDINA, N.M. Elementos para a introdução da dimensão ambiental na educação escolar - $1^{\circ}$ grau. Amazônia: uma proposta interdisciplinar de Educação Ambiental. Brasília: IBAMA, 1994.

MEDINA, N.M. Formação de multiplicadores para Educação Ambiental. In: O contrato social da Ciência, unindo saberes na Educação Ambiental. PEDRINI, A. G. (Org.). Petrópolis: Vozes, 2002. 
NAKAYAMA, L.; SOARES, S. A.; PRIETO, C.; SANTANA, A.R.; DANTAS, O. M. S. Espaço de Leitura Profa. Ana Lúcia Santos de Jesus e a formação de grandes leitores em Belém- PA. Educação Ambiental em Ação. n. 22, 2007. Disponível em: http://www.revistaea.org/artigo. php?idartigo $=516 \&$ class $=21$. Acesso: em 09/04/12009.

OLIVEIRA, M.K. Vygotsky: aprendizado e desenvolvimento, um processo sócio-histórico. São Paulo: Scipione, 1993.

PARRA, N.; PARRA, I. C. C. Técnicas audiovisuais de Educação. São Paulo: Pioneira, 1985.

PRADO, F. A utilização da mímica como recurso psicopedagógico, 2009. Disponível em: http://www.portalensinando.com.br/ensinando/ principal/conteudo.asp?id=4315. Acesso em: 11/04/2009.

PINTO, G. R. A gotinha Plim Plim. Belo Horizonte: FAPI, 1994.

PULASKI, M. A. S. Compreendendo PIAGET: uma introdução ao desenvolvimento cognitivo da criança. Rio de Janeiro: RTC, 1980.

RECHINELI, L. R.; FERREIRA, A. S.; FERREIRA, C. G.; ASSUNÇÃO, I. L. Vivendo o letramento: práticas cotidianas na educação infantil. EMEI "Casinha Feliz" Campinas: Secretaria Municipal de Educação de Campinas, 2008. Disponível em: http://www.alb.com.br/ anais16/sem10pdf/sm10ss05 07.pdf. Acesso em: 19/03/2009.

SANTOS, S. M. P. A ludicidade como ciência. Petrópolis: Vozes, 2008.

SILVA, M. L. Múltiplas falas, saberes e olhares. In: Os encontros de Educação Ambiental no estado do Pará. Belém: SECTAM, 2005.

Tratado de Educação Ambiental para sociedades sustentáveis e responsabilidade global, 1992. Disponível em: http://www.ufpa.br/ npadc/gpeea/DocsEA/TratadoEA.pdf. Acesso em: 24/02/2009.

WIKIPEDIA. Enciclopédia Livre. Disponível em: http://www. pt.wikipedia.org/wiki/Gincana. Acesso em: 24/03/2009. 